\title{
Is lathyrism still endemic in northern Ethiopia? - The case of Legambo Woreda (district) in the South Wollo Zone, Amhara National Regional State
}

\author{
Redda Tekle Haimanot ${ }^{1}$, Amsalu Feleke ${ }^{2}$, Fernand Lambein ${ }^{2}$
}

\begin{abstract}
Background: Lathyrism is a neurotoxic disorder caused by over consumption of grass pea (lathyrism sativus). It is endemic in Ethiopia, India and Bangladesh. The fact that grass pea usually tends to replace the staple serial based diet of rural north and central Ethiopia during times of acute food shortages, makes the disease particularly important in the Ethiopian context.

Objective: This study is aimed at investigating on whether lathyrism is still endemic in northern Ethiopia based on the March 26, 2004 report that appeared on the Amharic daily Addis Zemen, which indicated the occurrence of an epidemic where 400 people have been paralyzed in Legambo Woreda, south Wollo, Zone of ANRS.

Methods: A house-to-house survey of 3,440 households was undertaken in Legambo Woreda, south Wollo Zone of the Amhara National Regional State, using pre-tested questionnaires. The study subjects were identified as persons with walking difficulties due to weaknesses of the legs.

Results: The study identified 424 cases of lathyrism which occurred over many years in the woreda which has a population of 171,976 , which gives a prevalence of $2.5 / 1000$. Specifically the survey revealed that there were 48 cases with onset occuring in 1997, 54 in 1998, 55 in 1999, 38 in 2000 and 37 in 2001. The study further revealed that there is ongoing endemicity of lathyrism in this typical highland woreda of north Ethiopia.

Conclusion: It important that lathyrism gets the attention of relevant governmental agencies that should ensure the existence of early waring systems to deal with food shortages promptly so that the rural population does not resort to consuming large amounts of grass pea. Lathyrism has to also be a reportable disease within the Ministry of Health system in those areas of northern Ethiopia when grass pea is cultivated. [Ethiop.J.Health Dev. 2005;19(3):230-236]
\end{abstract}

\section{Introduction}

Lathyrism is a neurotoxic disorder characterised by spastic paraparesis, which is caused by the prolonged over-consumption of grass pea (Lathyrus sativus). The toxin within the grass pea which is held responsible for the paralysis is beta-N-oxalyl-diaminopropionic acid (ODAP) a non-protein, and neuro-excitatory amino acid (1). The irreversible spastic paraparesis has been well documented in studies in Ethiopia (2-5), India $(6,7)$ and Bangladesh (8).

Grass pea (Lathyrus sativus L., Guaya in Amharic, Gayyo in Oromiffaa, Sebere in Tigrigna) is an environmentally hardy legume which tends to replace the staple cereal- based diet of the people of rural north and central Ethiopia during times of acute food shortage. As a result of its drought-tolerant nature, grass-pea is extensively cultivated in the highlands of north and central Ethiopia where cases of lathyrism are seen both sporadically and in the form of epidemics.

On March 26, 2004 an article on the Amharic Newspaper, Addis Zemen reported the occurrence of a lathyrism epidemic in the sub-district (Woreda) of Legambo, south Wollo zone, Amhara National Regional
State (9). Reportedly, 400 people were paralysed from the disease. The report in the newspaper was based on an interview with an agriculture extension worker in the area. Reading the article an immediate question posed was: are we dealing with "yet another epidemic" of lathyrism in northern Ethiopia? Dembia and Fogera Woredas in Gondar zone also suffered a major epidemic in 1976/77 when over 2500 people were paralysed (2). A second epidemic following the drought of 1995/96 in North Wollo resulted in 2000 cases of lathyrism in Delanta Dawint Woreda (5). The authors of this study decided to take the newspaper's report at its face value to initiate further investigation. They reasoned that even if the report is proved to be a false alarm, it could nevertheless be used to examine the state of endemicity of the disorder in South Wollo. This was the purpose and aim of this study.

\section{Methods}

The first and second authors visited the Agricultural and Health bureaus of the Amhara Regional State in Bahr Dar to explain the purpose of the survey. Discussions were held with responsible officials of the ministries as well as the Amhara Agricultural Research Institute. The investigators inquired if the officials were aware of the

\footnotetext{
${ }^{1}$ Dept. of Internal Medicine, Faculty of Medicine, Addis Ababa University, Ethiopia; ${ }^{2}$ Gondar College of Medicine and Health Sciences, University of Gondar, Gondar, Ethiopia; ${ }^{3} \mathrm{IPBO}$, Ghent University, Ledeganckstraat 35, 9000 Ghent, Belgium $<$ fernand.lambein@Ugent.be $>$
} 
newspaper's report about the onset of an epidemic of lathyrism in South Wollo. In addition, the whole issue of over-production and consumption of grass pea in the Amhara National Regional State was also taken up in the discussions.

Following the Bahr Dar visit, permission was secured to undertake a lathyrism survey in Legambo Woreda, (subdistrict) South Wollo zone. The necessary official letter was obtained. Through the health desk of the South Wollo Zone, two health officers from Dessie and ten field workers from Legambo were identified and employed on short-term contracts. The health officers were instructed on their roles as supervisors of the field survey in Legambo. The overall study was coordinated by the second author, an Assistant Professor in the Department of Community Health of the Gondar College of Medicine and Health Sciences. The high school graduates employed as field workers were trained in the recognition of cases of lathyrism and in the accurate completion of questionnaires. Video recordings of lathyrism cases exhibiting different stages of spastic paraparesis were shown to them. They were also given the opportunity of observing and examining real patients that have the disease.

Four questionnaires were prepared for the survey. These were well-tested instruments used in previous studies in north Ethiopia $(3,4)$. The first questionnaire was designed to collect information from representatives of the office of the Ministry of Agriculture on the extent of grass pea cultivation, the climatic conditions and cases of lathyrism seen in the Woreda over the last five years. The second questionnaire addressed health professionals. It was formulated to find out the professionals' knowledge of the causes of lathyrism in relation to grass pea consumption and whether lathyrism was a reportable disease in the health delivery system. Their opinion on what preventive measures should be implemented to mitigate the problems of lathyrism was also solicited. The first and second questionnaires were completed through interviews conducted by the health officers.

The third questionnaire was used to gather information from the leadership of Peasant Associations. Climatic conditions, cultivation and consumption of grass-pea (during normal and food shortage times) and preventive actions against lathyrism were investigated. The fourth questionnaire was designed for the house-to-house interviews by lay health workers to identify cases of lathyrism and to find out the period and manner of grasspea consumption before the onset of paralysis. In the affected cases, the year of onset of paralysis and other associated conditions and illnesses, such as fever, diarrhoea, strenuous physical duties were also included as questions. All cases of lathyrism identified by field workers were examined and the final diagnosis was confirmed by the health officers. Those cases with weakness of the legs due to traumatic and non-lathyrism neurological causes were excluded.

Consent for interviews and examinations were obtained from all the participants of the study. For the rural communities explanation was made on the purpose and importance of the study through village leaders.

\section{Results}

The Legambo Woreda is situated on the beautiful highlands of South Wollo at an altitude of about 3000 meters above sea level (Figure 1). It is populated by relatively poor farming communities. According to the 2004 local zonal census, the population of Legambo Woreda was 171,976 with a male to female ratio of $1: 1.05$. Over a period of two months the trained enumerators made house-to-house interviews of 3,440 households. Within this Woreda, 424 cases of lathyrism were discovered which makes the prevalence of the disorder to 2.5 per a thousand, population. In 33 households more than one member of a family was found to be affected by lathyrism. Out of all the affected cases, $19.8 \%$ were females and $80.2 \%$ were males. The majority $(43.3 \%)$ were in the $10-20$ year age group (Table). Categorisation of the cases into the year of onset revealed that the highest numbers were in 1997 (48 cases), 1998 (54 cases), 1999 (61 cases), 2000 (38 cases), 2001 (37 cases). It was also found that cases of lathyrism ranging from 2 to 61 have been seen yearly since 1931 .

\begin{tabular}{|c|c|c|c|}
\hline Age distribution & $\mathbf{M}$ & $\mathbf{F}$ & Total \\
\hline $0-10$ & 29 & 19 & 48 \\
\hline $11-20$ & 148 & 36 & 184 \\
\hline $21-30$ & 60 & 15 & 75 \\
\hline $31-40$ & 40 & 7 & 47 \\
\hline $41-50$ & 32 & 3 & 35 \\
\hline $51-60$ & 13 & 3 & 16 \\
\hline $61-70$ & 11 & 1 & 12 \\
\hline $70+$ & 7 & - & 7 \\
\hline $\begin{array}{l}\text { Total } \\
\%\end{array}$ & $\begin{array}{r}340 \\
80.2\end{array}$ & $\begin{array}{r}84 \\
19.8\end{array}$ & $\begin{array}{r}424 \\
100.0\end{array}$ \\
\hline
\end{tabular}

From the information gathered from extension workers of the Ministry of Agriculture, it was found that shortage of rains occurred in the years, 1997, 1998 and 1999. During the interview of the extension workers it was learnt that there were wrong beliefs and misconceptions on the causation of lathyrism. Although the agricultural workers were convinced that grass pea was the root cause of lathyrism, there were misconceptions like the important role played by the inhalation of the vapour or smoke of grass pea during boiling and roasting. They also wrongly assumed that dehusking was an effective method of reducing toxicity. Similarly, wrong beliefs were also held by some of the health professionals. What also transpired during the interview of the health 
professionals was the fact that lathyrism was not a disease that needed to be reported in the routine reporting system of the Ministry of Health.

Interviews with peasant associations revealed that in normal times grass pea was consumed in moderate amounts in boiled ("Nifro"), powdered ("Shiro") and raw forms. However, the amount of consumption of the different forms increase dramatically during times of food shortage. In addition to the forms already mentioned, the legume was also consumed in the form of bread when cereals were in short supply or are not available.

\section{Location Map of LEGAMBO wereda in Amhara region}

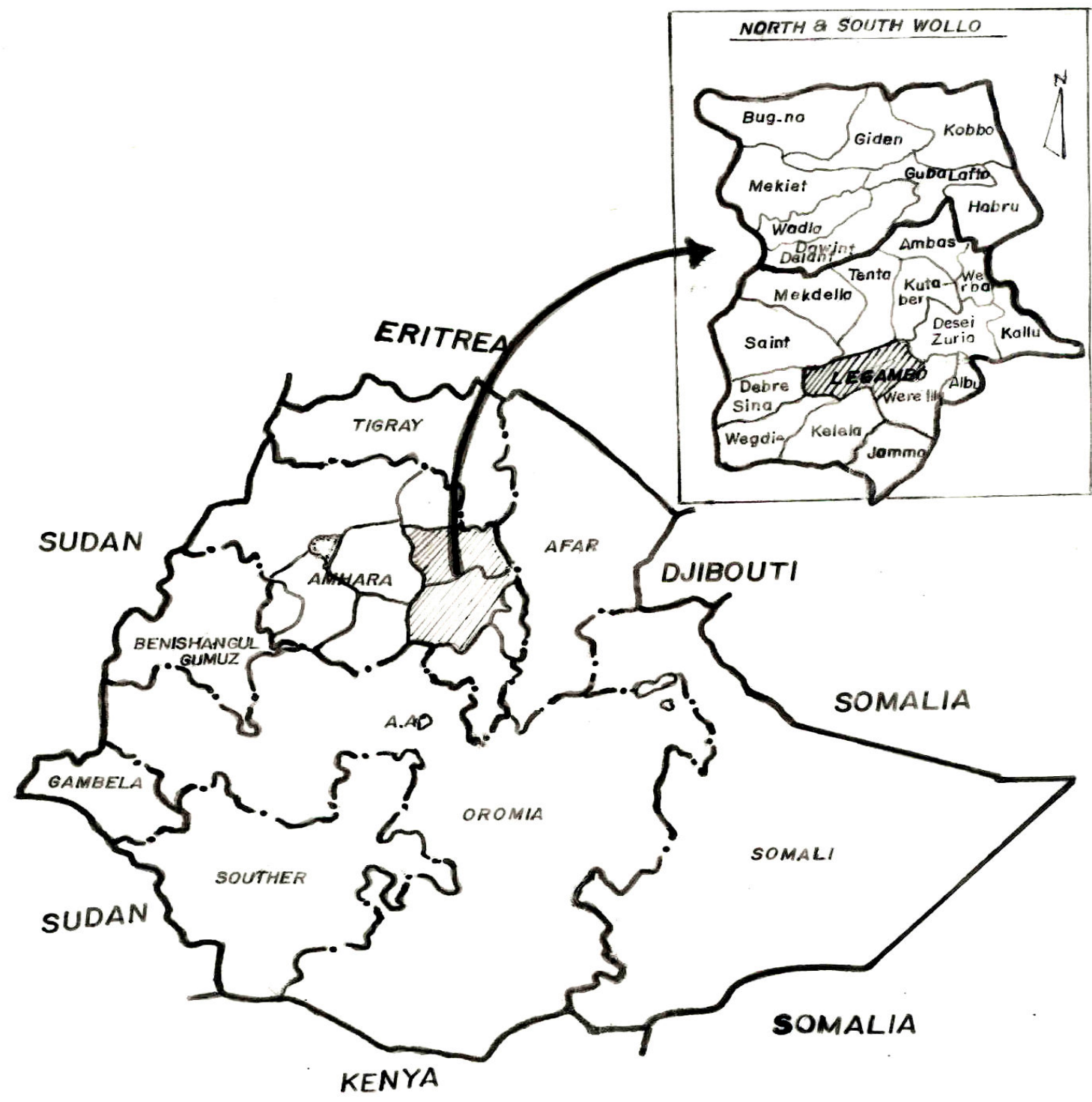

Figure 1: Location map of LEGAMBO Wereda in Amhara region on northern Ethiopia

\section{Discussion}

This study was not conducted to make an in depth clinical investigation of lathyrism in Ethiopia. This has been done and reported in detail in previous studies (2-5,
9). What prompted this field survey was the newspaper's report based on interviews with the agricultural extension workers referred to at the beginning of this paper. During the survey, the supervisors met and talked to the 
agricultural expert himself. It was obvious that what he reported concerned total cases of lathyrism rather than a recent epidemic of the disease in the Woreda. In any case, his astute observation is most remarkable and commendable. He wanted to raise awareness on the plight of the rural population under his observation and the need for instituting preventive measures against the devastating dangers of the paralyzing disease. Did he get the appropriate response? The answer is obviously no, because surprisingly no one in the Agricultural or the Health Departments at the zonal or regional levels was aware of the Addis Zemen report. In fact, all officials that were met during this study were taken by surprise when the newspaper cutting was showed to them.

What was found in this study is a confirmation that the epidemiology and clinical manifestations of lathyrism in Legambo Woreda are very similar to those reported earlier in other parts of Ethiopia (2-5) and the situation in the Indian subcontinent $(6,8)$. The predominantly young male predilection is very typical of lathyrism. However, the issue that we want to take up and underline in this paper is the underreporting and neglect of this public health problem at various levels. Nearly all cases of the disease do not seek the attention of the existing health services. The reasons for not reporting are varied. The major one is the accepted understanding among the rural population that there is no cure for lathyrism. However, even if such cases were to come to health posts, there was no system in place to report the situation to higher authorities. This underreporting makes it impossible to determine the true extent of this public health problem. Therefore, the endemicity and occasional epidemics fail to get the appropriate attention of governmental agencies.

The existing disease burden reporting system of the Ministry of Health does not include lathyrism for the obvious reason that it is not seen as a major, national public health problem. However, considering the fact that many young and productive members of the society, often the bread earners of the family, fall victims to the devastating irreversible paraparesis, we strongly believe that some method of active surveillance and timely reporting should be organised and enforced for the grass pea growing areas of the Amhara and central Oromiya Regions. Such reports are obviously extremely important to plan appropriate interventions and to put in place the preventive measures they deserve. After the reported and documented epidemics of 1995-1996 in the nearby Elanta-Dawint Woreda (5), dozens of lathyrism cases continued to develop each year in Legambo Woreda for at least five years, unreported and unnoticed. As far as we know, a recent national survey on the accurate extent of the lathyrism situation in Ethiopia has not been done and the situation in Legambo might well be typical for all drought prone grass pea growing areas in northern Ethiopia.
It is obvious from this study that lathyrism is very much an endemic disease among the poor rural populations of northern Ethiopia. Such farming communities lead a hand-to-mouth existence. When the rain fails they have no alternative other than to cultivate the drought resistant grass pea. People residing outside the lathyrism endemic areas of northern Ethiopia tend to take the simplistic approach of the "why do they not stop eating grass pea". This is an impossible option in the context of the situation in northern Ethiopia, where recurrent droughts and occasional floods force poor rural farmers to depend on grass peas for their subsistence. In fact, the cultivation and production of grass pea is ever increasing in the Amhara National Regional State. For some farmers grass pea is also an income generating cash crop because of its high demand in central Ethiopia as a tasty adulterant for the preparation of "Shiro" the powdered form of grass pea. It has been found that small amounts of grass pea used in shiro and consumed in the form of a sauce to be served with "injera" (unleavened bread) is harmless.

Since there are no early warning mechanisms the rural populations in grass-pea growing areas are not provided with supplemental grains to carry them over the hard times of food shortage. There is good evidence to show that mixing cereals with grass pea would go a long way to reduce toxicity and thus prevent lathyrism (15). The authors of this study would like to strongly stress and plead for an early warning system of food shortage in all grass pea endemic areas and an immediate response with a supply of cereals to susceptible populations. Here, the government has a big responsibility.

There are simple methods of reducing the amount of toxin (Diamino Proprionic Acid- ODAP) in the seeds of grass pea. There are promising research efforts that help to develop low toxin varieties of grass pea. However, it takes some time until the experts provide firm evidence that such varieties could maintain their low ODAP levels when grown in different soils and at different locations in the country. There will also be the issue of acceptability of the newly developed low toxin varieties by the rural farmers.

There are home based approaches for reducing the toxicity of grass pea. Boiling the grass pea and decanting the excess water would leach out the water-soluble toxic amino acid by $30-50 \%(9-10)$. This simple approach of steeping can be used when preparing the boiled and shiro forms of grass pea. Fermentation of grass pea also reduces the toxin and improves the balance of nutrients (11-14).

The agricultural and health extension workers can play pivotal role in the control and prevention of lathyrism in the rural communities where the most productive members are affected by the disorder. In order to avoid 
misconceptions and to improve the knowledge of agricultural and health extension workers, educational programmes focussed on health are essential. Flyers, pamphlets and radio programmes also need to be prepared in order to transmit clear and simple messages about the causes, dangers and prevention of the disease. One of the simplified and informative flyers prepared for distribution in the Amhara National Regional State are attached as an annex. This flyer which is, simple, easy to read and handle is a product of this survey.

\section{Acknowledgement}

This study was supported by the Flemish Inter-University Council, Belgium. We are grateful to the health officers from the south Wollo health desk who supervised the study and the lay health workers from Legambo Woreda who performed the field survey.

\section{References}

1. Spencer PS, Roy DN, Ludolph A, Hugon J and Schaumberg HH. Lathyrism: Evidence for role of the neuroexcitatory amino acid BOAA. The Lancet 1986, ii: 1066-67.

2. Gebreab T, Wolde Gabriel Z, Maffi M, Ahmed Z, Ayele T and Fanta H. Neurolathyrism: a review and report of an epidemic, Ethiop Med 1978;16:1-11.

3. Tekle-Haimanot R, Kidane Y, Wuhib E, Kalissa A, Alemu T, Zein AZ. and Spencer P.S. Lathyrism in rural Northwestern Ethiopia: A highly prevalent neurotoxic disorder. Int J Epid 1990; 19: 664-672.

4. Tekle-Haimanot R, Kidane Y, Wuhib E, Kalissa A, Alemu T, Yohannes $\mathrm{E}$ and Spencer PS. The epidemiology of lathyrism in north and central Ethiopia. Ethiop Med J 1993; 31: 15-24.

5. Getahun H, Mekonnen A, Tekle-Haimanot R. and Lambein F. Epidemic of neurolathyrism in Ethiopia. The Lancet 1999, 354: 306-307.

6. Dwivedi M.P and Prasad V.G. An epidemiological study of lathyrism in the district of Rewa, Madhya Pradesh. Ind J Med Res 1964; 52: 81-114.

7. Ganapathy KT. and Dwivedi MP. Studies on clinical epidemiology of lathyrism. Lathyrism Enquiry Field Unit, Indian Council of Medical Research, Ghandi Memorial Hospital, Rewa, Madhya Pradesh, India. 1961.

8. Haque A, Hossain M, Wouters G and Lambein F. Epidemiological study of lathyrism in North-western districts of Bangladesh. Neuroepidemiology 1996; 15: 83-91.

9. Addis Zemen Newspaper March 26, 2004 (Amharic Language).

10. Tekle-Haimanot R, Abegaz B, Wuhib E, Kassina A, Kebede N, Kidane Y, Alemu T and Spencer P.S. Pattern of Lathyrus Sativus (Grass Pea) consumption and $\beta$-N-Oxalyl- $\alpha, \beta$-Diaminopropionic acid ( $\beta$ ODAP) content of food samples in the Lathyrism endemic region of northwest Ethiopia. Nutrit Res 1993; 13: 1113-1126.
11. Mohan V S, Nagarajan V and Gopalan C. Simple practical procedures for the removal of toxic factors in Lathyrus sativus (Khesari dal). Ind. J. Med. Res. 1966; 54: 410-9.

12. Naved A F, Roy B C, Chowdhury AKA, Yusuf HKM. Some methods for removal of Lathyrus toxin. Bangladesh J. Agric. 1989; 14: 279-286.

13. Yigsaw Y, Gorton L, Akalu G, Solomon T. Fermentation of teff (Eragrostis tef), grass pea (Lathyrus sativus) and their mixtures: Aspects of nutrition and food safety. Lathyrus Lathyrism Newsletter 2001; 2:8-10.

14. Kuo YH, Bau HM, Quemener B, Khan JK and Lambein F. Solid state fermentation of Lathyrus seeds using Aspergillus oryzae and Rhizopus oligosporus sp $\mathrm{T} 3$ to eliminate the neurotoxin B-ODAP without loss of nutritional value. J Sc Food Agr 1995; 69:81-89.

15. Lambein F, Ngudi DD, Kuo YH. Vapniarca revisited: Lessons from an inhuman human experience. Lathyrus Lathyrism Newsletter 2001; 2: 5-7.

Annex: Flyer on lathyrism and its prevention

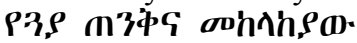

1. $3, \rho 903,9.340 \cdot ?$

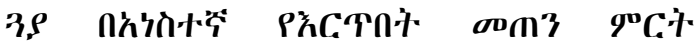

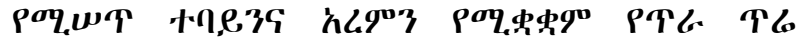

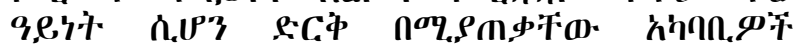

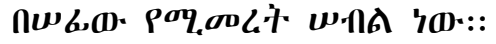

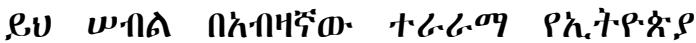

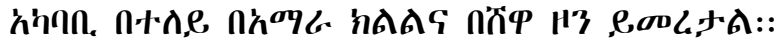

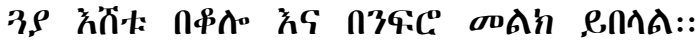

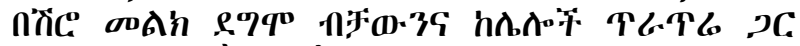

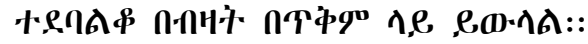

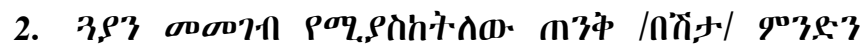
id)::

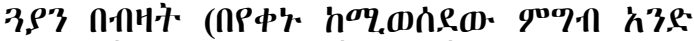

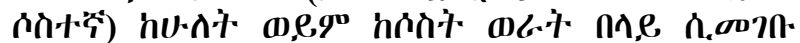

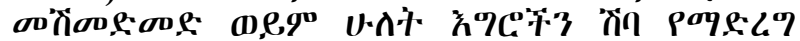

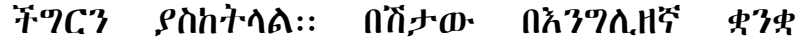

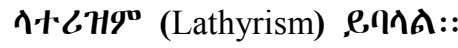

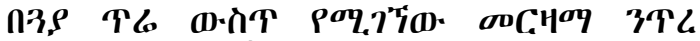

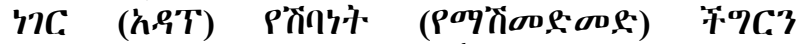
คOq.P

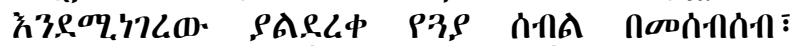

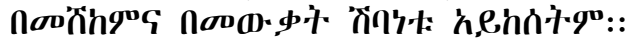

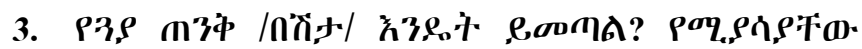

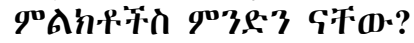

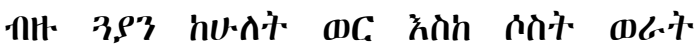

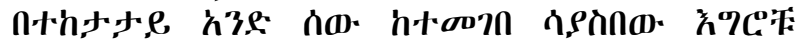

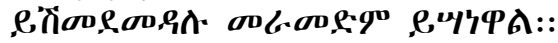

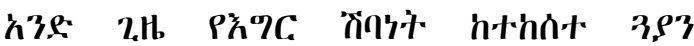

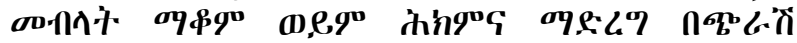

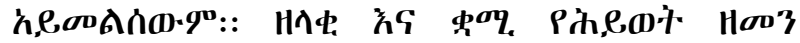


等\%C

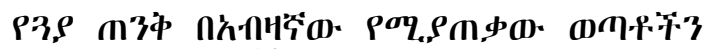

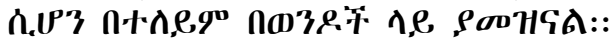

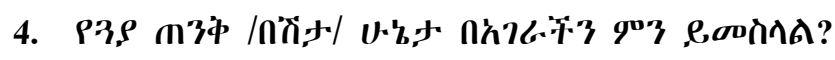

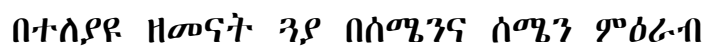

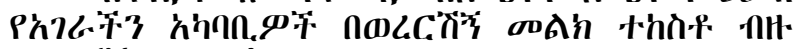

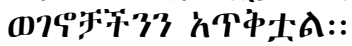

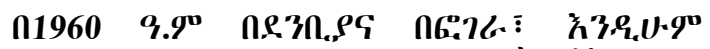
01987 9.90 nq. ब.

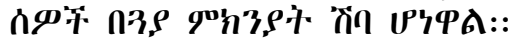

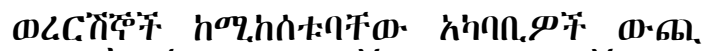

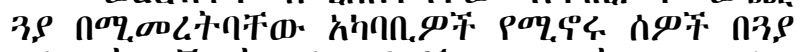

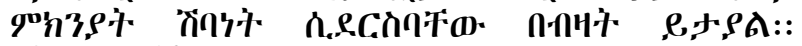

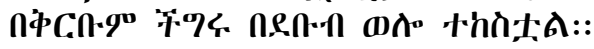

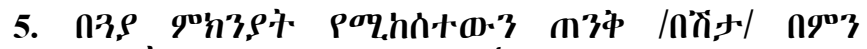
h,

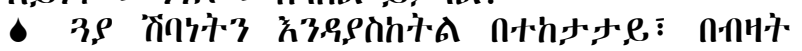

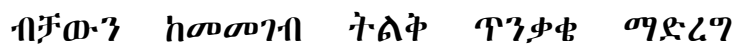
Sก6.A.ग::

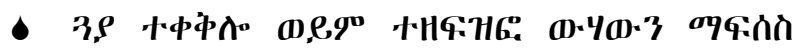

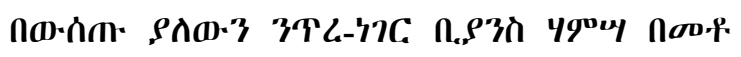

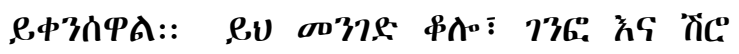

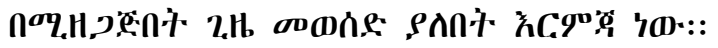

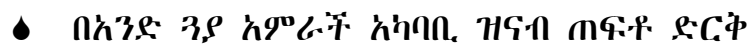

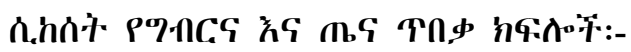

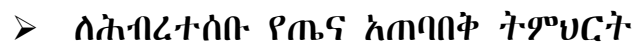

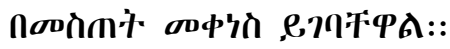

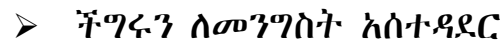

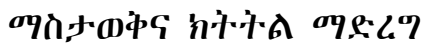
EqC.TFPA::

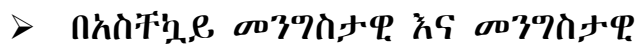

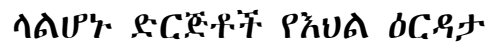

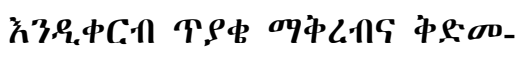

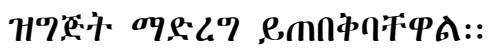

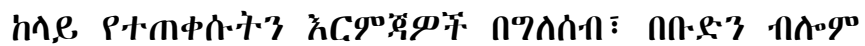

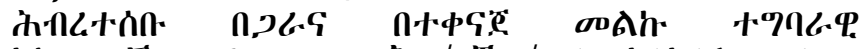

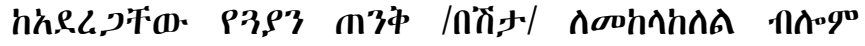

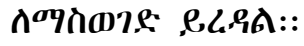

Annex: English translation of flyer on lathyrism and its prevention

\section{What is grass pea (Lathyrus Sativus)}

Grass pea is a legume which is environmentally resistant to drought, water, logging, pests and weeds. This legume is widely harvested in areas prone to drought.

This crop is widely produced in the highlands of northern and central Ethiopia, especially in the
Amhara National Regional State and Shoa Zone.

Grass pea seed is consumed in roasted, boiled and raw forms. It is also prepared as "Shiro" (flour form) alone or mixed with other legumes.

2. The Health effect of grass pea

Consuming too much of grass pea (over one third of ones daily dietary intake) continuously for more than two or three months results in paralysis of the legs. This paralysis is known as lathyrism in English.

The poisonous compound found in the seed of grass pea is called "ODAP". Unlike the misconception and wrong beliefs of guaya paralysis coming from harvesting the legumes or carrying it the real cause of paralysis is the consumption of grass pea and its poisonous component - ODAP.

3. How does the paralysis come about and how does it manifest.

If a person consumes grass pea continuously for two or three months she/he is likely to develop sudden paralysis of the legs which will make the person unable to walk. Once paralysis occur neither treatment nor discontinuation of consumption can reverse the problem.

Guaya paralysis mostly affects young people; particularly males.

4. What is the lathyrism situation in Ethiopia Lathyrism epidemics have occurred in different periods of time in the north and northwest parts of the country.

During the epidemic in 1960 E.C. in Dembiya and Fogera woredas and in 1987 E.C. in WaldaDelanta Woreda more than five thousand people were paralyzed.

In places where grass pea is cultivated many cases of paralysis still occur. Recently, many cases have been reported in south Wollo.

What are the methods to prevent lathyrism.

- The best method is to avoid excessive and continuous consumption of grass pea alone.

- Discarding the water which is used for cooking and socking reduces the poison with the seed by $50 \%$. This procedure should be followed when preparing the roasted, boiled or "Shiro" forms of guaya.

- Whenever drought occurs in lathyrism endemic areas, agricultural and health officials should do the following:

Ethiop.J.Health Dev. 2005;19(3) 
$>$ They have to alert the communities and inform about the dangers of the paralytic disease.

$>$ They should immediately report the situation to higher governmental authorities.

$>$ Government and NGOs should supply supplemental food to the people affected by the drought in order to prevent the paralysis before it occurs.

Taking all the above measures by individuals, groups and communities in a concerted manner would help to control and possibly eliminate lathyrism. 
